\title{
Hybrid coagulation/ozonation treatment of pharmaceutical wastewater using ferric chloride, polyaluminum chloride and ozone
}

\author{
A. Shirafkan ${ }^{1} \cdot$ S. M. Nowee $^{1} \cdot$ N. Ramezanian $^{2} \cdot$ M. M. Etemadi ${ }^{1}$
}

Received: 25 May 2015/Revised: 30 December 2015/Accepted: 17 February 2016/Published online: 15 March 2016

(C) Islamic Azad University (IAU) 2016

\begin{abstract}
In recent years, concerns about the occurrence and fate of active pharmaceutical ingredients, solvents, intermediates and raw materials that could be present in pharmaceutical industry effluents have gained increasing attention. Conventional treatment methods, such as activated sludge, are not sufficient enough to remove active pharmaceutical ingredients completely. As a result, complementary treatment methods like coagulation and flocculation are often used and play a critical role in industrial and municipal wastewater treatment. The primary goal of these methods is to destabilize and remove colloidal particles along with other organic/inorganic contaminants. Recently empirical works have considered ozone as the most promising oxidant for the removal of micro-pollutants. The current study examined the effectiveness of coagulation/flocculation process using ferric chloride, polyaluminum chloride, and aluminum sulfate as a reasonable approach to tackle the issue of treating pharmaceutical wastewater. In addition, the results were compared with the process using only ferric chloride that was the coagulant of an actual treatment plant. Then, improvement of the process performance was investigated using ozone as an oxidant. In conclusion, it was found out that polyaluminum chloride presented better performance among two other coagulants and also adding $200 \mathrm{mg} / \mathrm{L}$ of polyaluminum chloride can lead to 97-98\% turbidity removal efficiency. Moreover, polyaluminum chloride was capable
\end{abstract}

S. M. Nowee

nowee@um.ac.ir

1 Chemical Engineering Department, Faculty of Engineering, Ferdowsi University of Mashhad, Mashhad, Iran

2 Chemistry Department, Faculty of Sciences, Ferdowsi University of Mashhad, Mashhad, Iran of reducing most of the environmental parameters such as chemical oxygen demand and total dissolved solid with the removal efficiency of 70 and $68 \%$, respectively. Additionally, ozonation improved the coagulation process, especially iron ion removal, and dramatically decreased the concentration from 5.68 to $0.19 \mathrm{mg} / \mathrm{L}$.

Keywords Coagulation - Environmental chemistry · Pharmaceuticals · Ozonation - Wastewater

\section{Introduction}

Over the last century, population growth and industrialization have resulted in the degradation of various ecosystems, upon which human life relies. In the case of oceans and rivers, such pollution is primarily caused by the discharge of inadequately treated industrial and municipal wastewater.

Effluents may contain high amount of inorganic pollutants, which can be easily biodegradable, while their impacts load on different ecosystems, "either in total suspended solids (TSS), total dissolved solids (TDS) biochemical oxygen demand (BOD), or chemical oxygen demand (COD)", may be in the tens of thousands of $\mathrm{mg} / \mathrm{L}$ (Ng 2006).

Chemical and pharmaceutical industries are allocated to a large group of industries. Various processes and a wide range of raw materials are applied to produce a set of products needed for providing regional demands. As a result, a large number of effluents with different characteristics and volumes are produced. These streams differ in relevant unit, time, and seasonal variation, which take place to produce certain medicines (Tzoupanos and Zouboulis 2008). Presence of pharmaceuticals and personal 
care products (PPCPs) was first identified in surface and wastewaters in the United States and Europe in 1960s (Stumm-Zollinger and Gordon 1965). In order to remove these contaminants from wastewater, physical, chemical, and/or biological methods can be used. Coagulation/flocculation is a commonly used chemical process in water and wastewater treatment. Natural coagulants like laterite soil have been applied to treat dye wastewater (Lau et al. 2014, 2015) or chemical-based coagulants such as ferric chloride $\left(\mathrm{FeCl}_{3}\right)$, aluminum sulfate (alum), and/or polymers are added to wastewater to destabilize colloidal materials and cause small particles to agglomerate into larger settable flocks (Amuda and Amoo 2007).

$\mathrm{FeCl}_{3}$ is a well-known coagulating agent in wastewater treatment, which is capable of removing color, organic matter, and heavy metals from wastewater (Errais et al. 2010; Papic et al. 2000; Golbaz et al. 2014). Recently, a number of alternative aluminum-based coagulants have been developed for water treatment applications. These compounds have the general formula $\left(\mathrm{Al}_{n}(\mathrm{OH})_{m} \mathrm{Cl}_{(3 n-m)}\right)_{x}$ and a polymeric structure.

Polyaluminum chloride ( $\mathrm{PACl}, n=2$ and $m=3$ ) is one of the most common coagulants in this group. Consumption of polyaluminum chloride has several advantages, including effectiveness in a wide range of $\mathrm{pH}$, low alkalinity, proper performance at low temperatures, and low levels of residual aluminum and chloride in the treated water that can reduce sludge production. It also requires lower doses than other coagulants (Gebbie 2001). Based on the studies some polymeric coagulants such as $\mathrm{PACl}$ have been found to be more effective and suggested for colorants removal of wastewater (Verma et al. 2012; Zahrim and Hilal 2013; Liang et al. 2014; Yeap et al. 2014).

Active pharmaceutical ingredients (APIs), in some cases, are not degraded sufficiently by biological processes during wastewater treatment, either because of the high persistence to biodegradation, or limited biological activity during treatment. Improving wastewater treatment plants by implying further technologies such as chemical oxidation can be a probable approach (Ternes et al. 2003; Hansen et al. 2010; Lee and von Gunten 2010). It has been proven that oxidation techniques can effectively remove potential pollutants that cannot be degraded biologically in wastewater. The other benefit of oxidative treatment is its disinfectant effect (Ayyildiz et al. 2009).

Chemical oxidation with oxidants such as ozone $\left(\mathrm{O}_{3}\right)$, chlorine, chlorine dioxide $\left(\mathrm{ClO}_{2}\right)$, and peracetic acid is applied widely for the treatment of drinking water and wastewater. Out of these four oxidants, ozone has been considered the most promising oxidant for the removal of micro-pollutants (Huber et al. 2003; Lee and von Gunten 2010; Ternes and Joss 2006). Ozone is a powerful oxidizing agent in water and wastewater treatments. Once ozone dissolves in water, it reacts with a great number of organic compounds in two different ways, by direct oxidation as ozone molecule or by indirect reaction through formation of secondary oxidants like hydroxyl radical (Baig and Liechti 2001). Since ozone is unstable and is decomposed into elemental oxygen in a short amount of time, it is usually generated on-site (García Montaño et al. 2007). Applications of ozone can be generalized in two groups (Am Water Works Res et al. 1991):

- A powerful disinfectant and a strong oxidant to remove color and odor;

- An applied agent to eliminate trace of toxic synthetic organic compounds and to assist in coagulation.

Since all the treatment methods have their own drawbacks, alternative methods are needed for treating wastewater. In the literature, there are some pieces of evidence for applying coagulation and ozonation processes individually for wastewater treatment. However, to the best knowledge of the present authors, there are no detailed studies or comprehensive investigations on using coagulation and ozonation processes simultaneously for the treatment of wastewaters. Therefore, in this present work, $\mathrm{FeCl}_{3}$, alum, and $\mathrm{PACl}$ were used as coagulants in treating pharmaceutical wastewater. For this purpose, the maximum percentage of turbidity removal was determined at the optimum dosage and $\mathrm{pH}$, and an appropriate coagulant was ascertained. In addition, the improvement of process performance was investigated using ozone as an oxidizing agent. Moreover, since $\mathrm{S}^{2-}$ ion has strong precipitating properties, the use of sodium sulfide $\left(\mathrm{Na}_{2} \mathrm{~S}\right)$ as a bleaching agent and removing heavy metals is reported (Soya et al. 2010); at final stages of the proposed treatment in this study, $\mathrm{Na}_{2} \mathrm{~S}$ was also added to the streamline.

Finally, in order to evaluate each stage (coagulation, ozonation and precipitation), environmental parameters such as $\mathrm{pH}$, COD, TSS, TDS, and heavy metal removal percentage were analyzed. This work was carried out at Department of Chemical Engineering, Ferdowsi University of Mashhad and some experimentation at Faculty of Health, Medical University of Mashhad, Iran, between June 2013 and January 2014.

\section{Materials and methods}

This study was set out with the aim of assessing the importance of wastewater treatment systems. The investigation was divided into three steps, coagulation-flocculation process, ozonation experiments, and sodium sulfide addition. 
The used wastewater effluents were collected from two points of the wastewater treatment line of a pharmaceutical plant: one sample from the input and another from the output streams of the coagulation step of the line.

Coagulation studies were performed using jar test (flocculator(apparatus from HACH Company (USA), equipped with six cylindrical beakers. The tests were performed using three coagulants $\left(\mathrm{FeCl}_{3}\right.$, alum, and $\left.\mathrm{PACl}\right)$. In order to determine the appropriate coagulant, the coagulation-flocculation process was carried out in two steps: first, to address the optimum $\mathrm{pH}$ and, then, to investigate the optimum concentration. Each experiment was performed by adding a certain amount of the coagulant into a beaker containing $0.5 \mathrm{~L}$ of the wastewater effluent with the initial $\mathrm{pH}$ value of 8.1 and initial turbidity of 156 NTU (Nephelometric turbidity unit). Then, the mixture was agitated at $150 \mathrm{rpm}$ for $1 \mathrm{~min}$ and at $40 \mathrm{rpm}$ for $15 \mathrm{~min}$. After completing the mixing operation, the mixture was given $60 \mathrm{~min}$ to settle; afterward, turbidity was analyzed. In order to optimize the $\mathrm{pH}$ value, the coagulation of wastewater was studied over the $\mathrm{pH}$ range of 4-9 at the coagulant dosage of $1000 \mathrm{mg} / \mathrm{L}$ for all the coagulants. The initial $\mathrm{pH}$ was adjusted by $1 \mathrm{~N} \mathrm{HCl}$ and $2 \mathrm{~N} \mathrm{NaOH}$ solutions. To optimize the coagulant dosage, coagulation experiments were carried out by varying dosage values in the range of $100-1200 \mathrm{mg} / \mathrm{L}$, at the optimum $\mathrm{pH}$ value obtained from prior experimentations. The treated wastewater by coagulation process was used to study the amount of turbidity removal.

The ozonation process was carried out after coagulation. In this step, two types of wastewater were selected: (1) The treated wastewater in the first step by the appropriate coagulant, and (2) the wastewater collected from the output of coagulation stage from the wastewater treatment plant, in which $\mathrm{FeCl}_{3}$ was used as a coagulant. The ozonation experiments were carried out in the laboratory. Ozone was generated from air using an ozone generator. All the experiments were performed at room temperature $\left(25^{\circ} \mathrm{C}\right)$ and the neutral $\mathrm{pH}(\approx 7)$ of wastewater. The ozone production can be set at $0.4 \mathrm{~g} \mathrm{O}_{3}$ per hour. The oxidized wastewater volume was $0.5 \mathrm{~L}$ in each experiment. The duration of the experiments was about $60 \mathrm{~min}$ and, as the last step of the experiment, sodium sulfide with a dosage $\approx 100 \mathrm{mg} / \mathrm{L}$ was added to the treated wastewater. This chemical possesses bleaching property as well as ability to remove heavy metals. Schematic diagrams of the pilot plant are presented in Fig. 1.

Finally, at the end of each experiment, environmental parameters such as $\mathrm{pH}, \mathrm{COD}$, TSS, TDS, and heavy metal removal percentage were analyzed in the laboratory according to the standards.

\section{Results and discussion}

This paper provides the account and reasons for the widespread use of wastewater treatment systems. The findings of this study have a number of important implications for the future practice. The coagulation-flocculation process was conducted for the treatment of colloidal particles in wastewater. Numerous jar tests were carried out in order to establish a practical understanding of the coagulation performance and to find optimum $\mathrm{pH}$ and coagulant dosage.

\section{Effect of $\mathrm{pH}$ on coagulation}

Since coagulation-flocculation processes take place in the specific range of $\mathrm{pH}$ for each coagulant; this parameter plays a key role in these processes. In this study, a wide range of $\mathrm{pH}$ (4-9) was selected to process at laboratory in two ways.

Figure 2 shows the effect of $\mathrm{pH}$ on the turbidity removal efficiency for different coagulants (alum, $\mathrm{PACl}$, and $\mathrm{FeCl}_{3}$ ). To determine the optimum $\mathrm{pH}$ value, the coagulant dosage was constant at $1 \mathrm{~g} / \mathrm{L}$. One of the most significant findings emerging from this study was that the best turbidity removal efficiencies were achieved at $\mathrm{pH} 5$ for PACl and $\mathrm{FeCl}_{3}$ and, at $\mathrm{pH}$ 6, for alum with maximum turbidity removal efficiencies of $98.74,94.68$, and $95.67 \%$. At high $\mathrm{pH}$ values, the flocs could not settle due to their small size. Hence, the wastewater had higher turbidity in this $\mathrm{pH}$ range.

Moreover, $\mathrm{pH}$ controls hydrolysis elements during coagulation process. When a coagulant such as aluminum or ferric salt is added to water, a series of soluble hydrolysis species is formed. These hydrolysis species have positive or negative charges depending on the $\mathrm{pH}$ of water. They are positively charged at low $\mathrm{pH}$ values $(\mathrm{pH}<6)$ and negatively charged at high $\mathrm{pH}$ values. The positively charged hydrolysis species can be absorbed onto the surface of colloidal particles and destabilize the stable colloidal particles. This mechanism is called "charge neutralization." The precipitate of aluminum or ferric hydroxide is formed at a sufficiently high coagulant dosage. These precipitates can physically sweep the colloidal particles from the suspension, which is called "sweep-floc coagulation" (Ayguna and Yilmazb 2010). In this study, after adding coagulants, coagulation mechanism showed the properties of charge neutralization coagulation due to low operation $\mathrm{pH}$.

\section{Determining optimal coagulant dosage}

Effect of coagulant doses on turbidity removal efficiency was also investigated and the results are presented in 

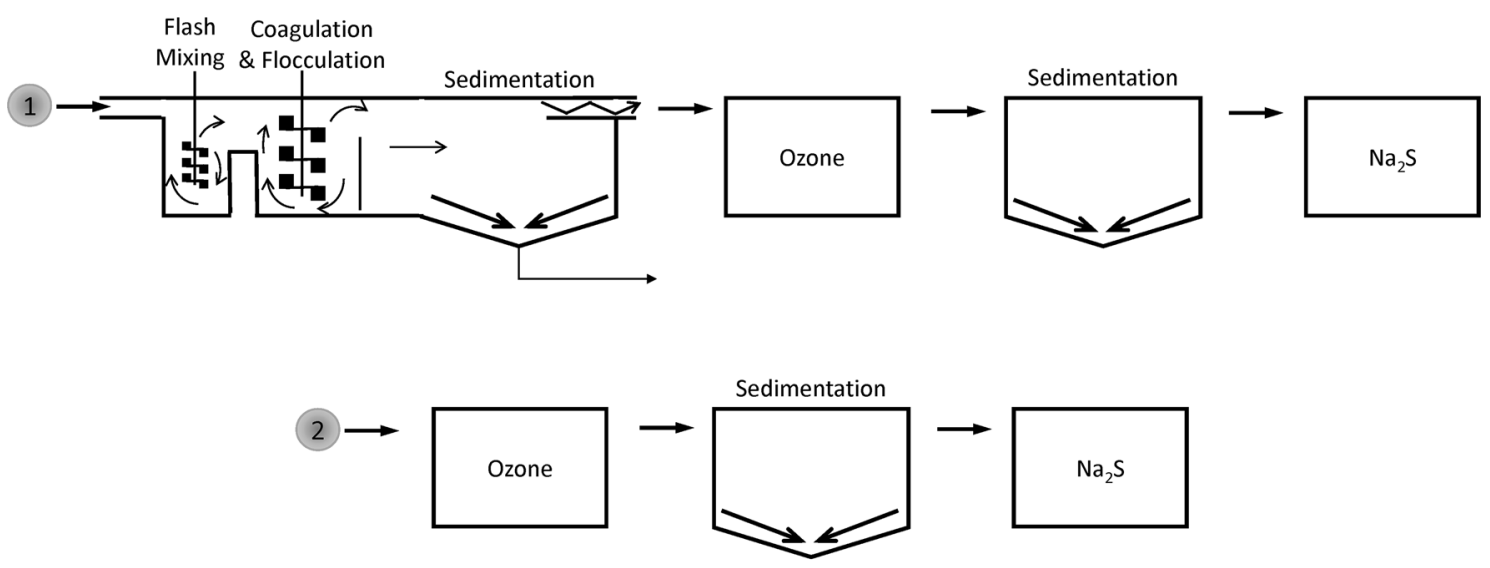

Fig. 1 Flow diagrams for treatment process at laboratory in two ways

Fig. 2 Effect of pH on turbidity removal by various coagulants at constant dosage $(1 \mathrm{~g} / \mathrm{L})$

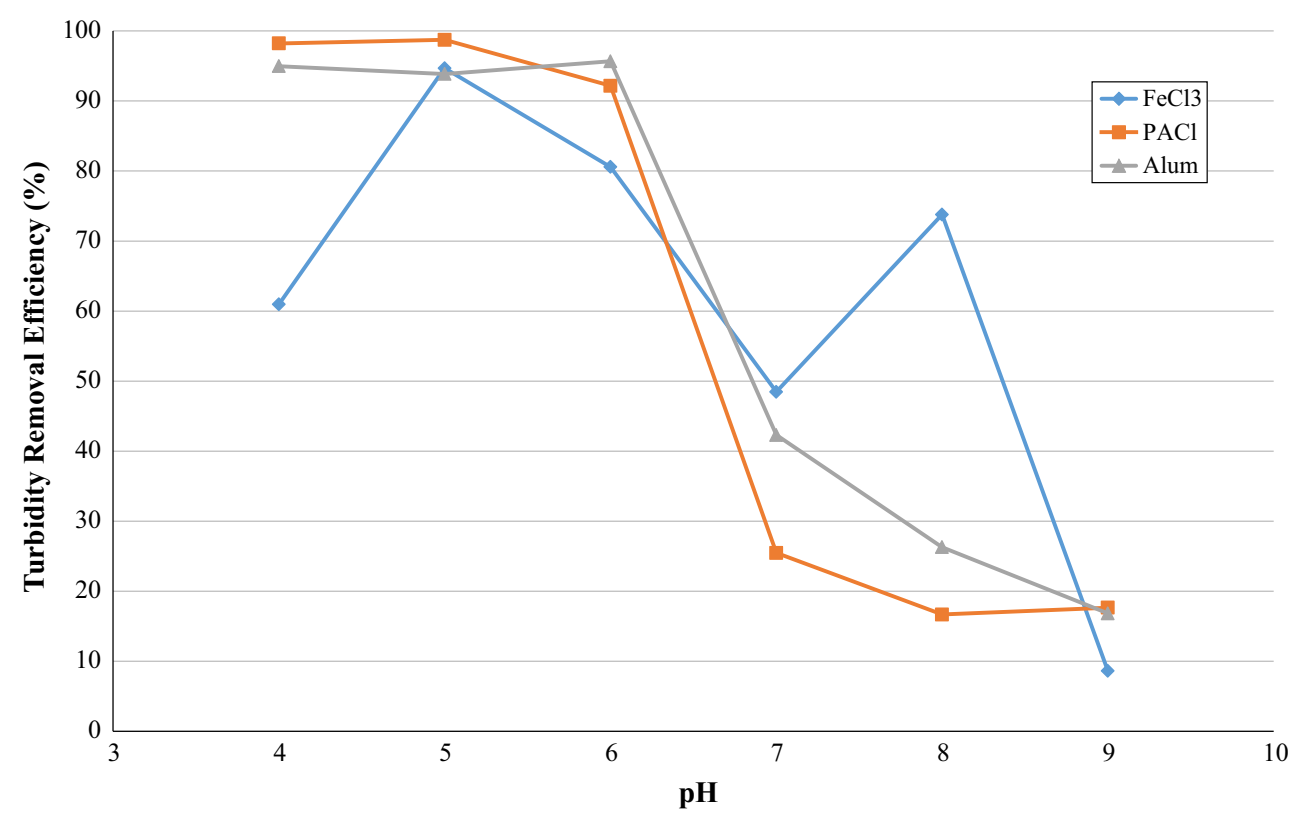

Fig. 3. The experiments were performed in the range of $(0.1-1.2) \mathrm{g} / \mathrm{L}$ of coagulant concentrations at the obtained optimum $\mathrm{pH}$ values. At the concentration of $0.2 \mathrm{~g} / \mathrm{L}$ for $\mathrm{PACl}$ and $\mathrm{FeCl}_{3}$ and $1 \mathrm{~g} / \mathrm{L}$ for alum, the turbidity removal efficiencies were 97.86, 95.98, and $95.67 \%$, respectively, which was due to charge neutralization caused by various hydrolysis species. These values were accepted as the optimum doses. At high coagulant doses, metal hydroxides were produced and organic substances were removed by incorporation or sorption onto hydroxide flocs. Such results corroborated the findings of Ayguna and Yilmazb in this field (Ayguna and Yilmazb 2010).

Since the generation of large hydroxide flocs could cause sweep coagulation, turbidity removal efficiencies for
$\mathrm{PACl}$ and alum did not change by increasing the coagulant dosage from the optimum value to $1.2 \mathrm{~g} / \mathrm{L}$.

There was an unpredictable result at the concentration of $0.8 \mathrm{~g} / \mathrm{L} \mathrm{FeCl}$, which was due to the variations of wastewater $\mathrm{pH}$ that led to the charge reversal of colloids.

According to the aforementioned achievements, $\mathrm{PACl}$ showed better performance among these three coagulants, since it led to the maximum turbidity removal at lower dosage. Besides, laboratory observations showed that PACl generated less sludge than other coagulants at an equivalent dosage and flocs formed from $\mathrm{PACl}$ tended to settle quickly. 
Fig. 3 Effect of coagulant dosage on turbidity removal at optimum $\mathrm{pH}(\mathrm{pH}=5$ for $\mathrm{PACl}$ and $\mathrm{FeCl}_{3}, \mathrm{pH}=6$ for alum)

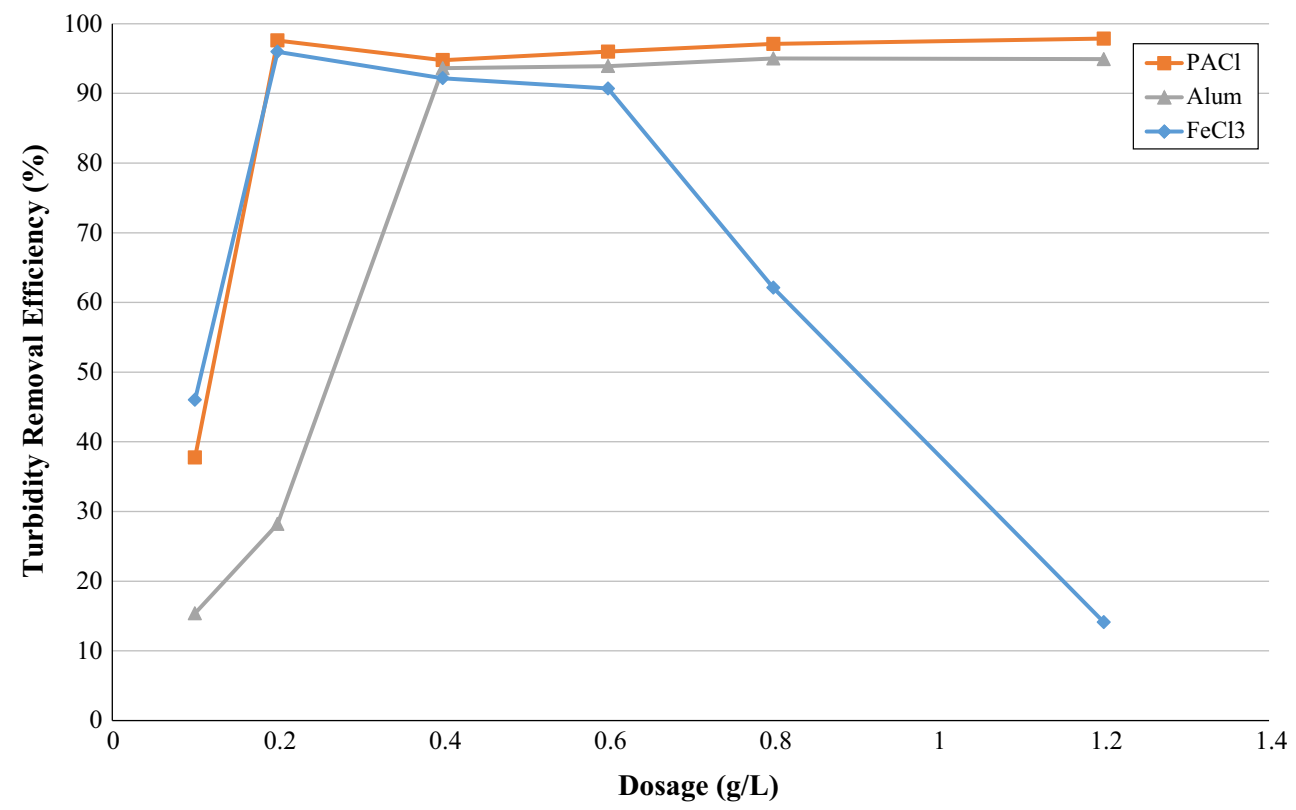

\section{Effect of different stages of treatment on environmental parameters}

$p H$

Different stages of treatment were carried out in two ways: (1) using the selected coagulant (PACl) and (2) using the employed coagulant in wastewater treatment plant $\left(\mathrm{FeCl}_{3}\right)$.

Figure 4 shows $\mathrm{pH}$ variation during different stages of the process. It can be seen that the addition of coagulants to the wastewater decreased $\mathrm{pH}$. For $\mathrm{PACl}$ and $\mathrm{FeCl}_{3}, \mathrm{pH}$ changed from 8.099 to 6.74 and 7.073 , respectively. Therefore, $\mathrm{PACl}$ provided an acidic ambience, whereas for $\mathrm{FeCl}_{3}, \mathrm{pH}$ remained in the neutral range. Clearly, ozone produced $\mathrm{OH}^{-}$which bonded with cationic ions present in the effluent and caused precipitation in form of metal hydroxyls. Therefore, ozonation did not result in significant change of the medium ionic balance. It is known that the presence of components (cations) in wastewater maintained a constant $\mathrm{pH}$, whereas removal of these

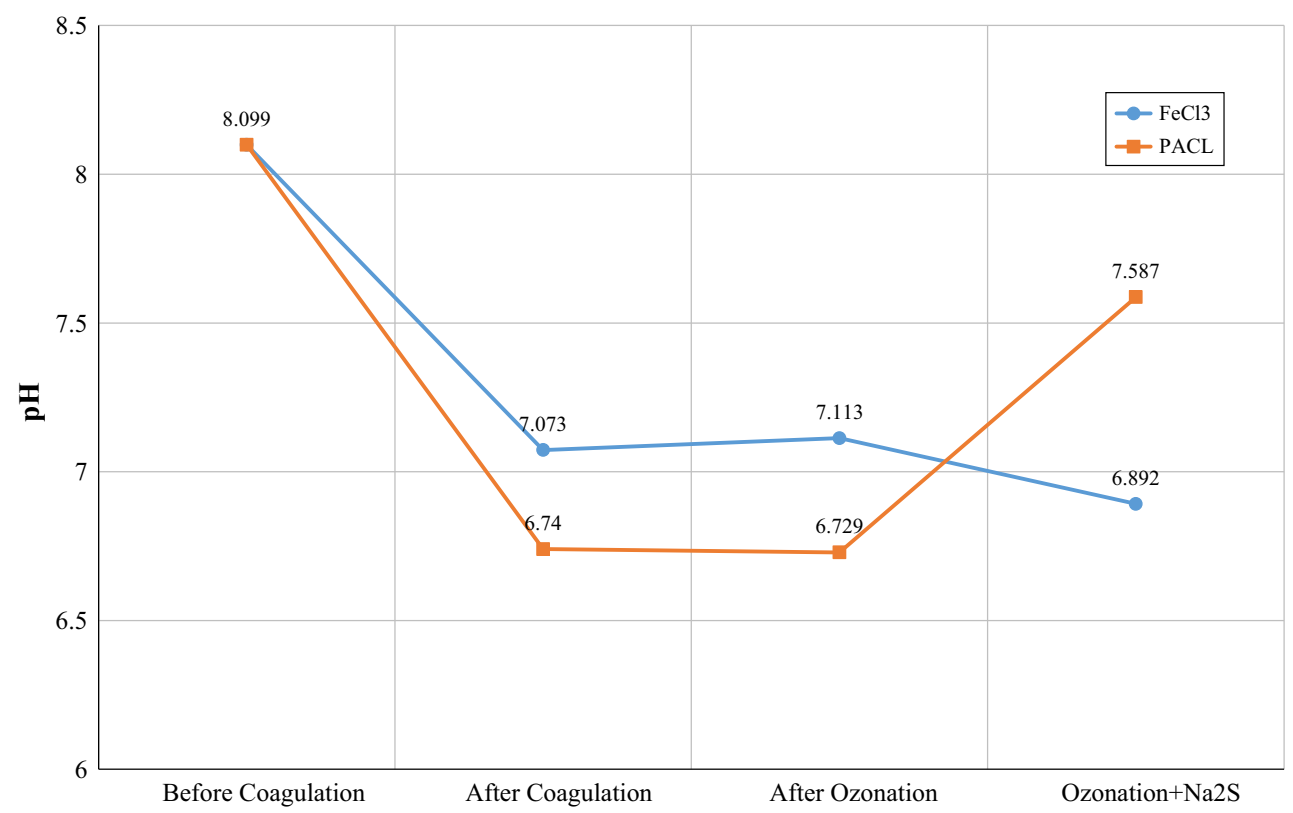

Fig. 4 Effect of different stages on $\mathrm{pH}$ 
components decreased pH (Kushwaha et al. 2010). From Fig. 4, pH did not change greatly and remained constant after ozonation.

In the final step, addition of $\mathrm{Na}_{2} \mathrm{~S}$ compound to the effluent increased $\mathrm{pH}$, where $\mathrm{PACl}$ was the coagulant, whereas using $\mathrm{FeCl}_{3}$ as the coagulant, $\mathrm{pH}$ was dropped to 6.9. This compound consists of $\mathrm{Na}^{+}$and $\mathrm{S}^{2-}$ ions, which can react with other ions in aqueous solutions like $\mathrm{Cl}^{-}$and $\mathrm{OH}^{-}$and cause an acidic or alkaline ambience. However, the important point is that both of these pathways are in accordance with EPA standards for effluent discharge to agricultural and irrigation waters.

\section{$C O D$}

Furthermore, the obtained effluent COD according to the applied treatment was analyzed. It was observed that the coagulation-flocculation process for all the cases decreased the effluent COD. As illustrated in Fig. 5, in the case of using $\mathrm{PACl}, \mathrm{COD}$ removal efficiency showed a sharp decline and better performance at this stage, whereas the reduction was around $50 \%$ for $\mathrm{FeCl}_{3}$.

Additionally, ozonation continued to reduce the effluent COD by almost 35 and $77 \%$ for $\mathrm{PACl}$ and $\mathrm{FeCl}_{3}$, respectively. Accordingly, the results of this step showed that, because by ozonation with $\mathrm{FeCl}_{3}$, coagulant $\mathrm{pH}$ variations were in the neutral and basic ranges where free radical mechanism occurred, higher removal efficiency than PACl was achieved. It should be noted that ozonation is a more efficient treatment when experimental conditions favor the free radical mechanism (García Montaño et al. 2007). Finally, adding $\mathrm{Na}_{2} \mathrm{~S}$ improved the treatment process. According to the results, the COD concentration drop continued up to 100 and $110 \mathrm{mg} / \mathrm{L}$ for $\mathrm{FeCl}_{3}$ and $\mathrm{PACl}$, respectively. These values were also in accordance with EPA standards.

\section{$T D S$}

A similar trend was observed for TDS reduction at different stages of the treatment process. According to Fig. 6, it can be seen that adding the coagulants sharply decreased the TDS of the effluent. For PACl and $\mathrm{FeCl}_{3}$, the TDS removal efficiency was 68 and $50 \%$, respectively. The greater value of TDS in the case of using $\mathrm{FeCl}_{3}(900 \mathrm{mg} /$ lit) was related to the higher release of $\mathrm{Cl}^{-}$ion by this coagulant, which in overall increased the TDS of the treated water (Gebbie 2001). Furthermore, by ozonation, the TDS continued to decline. Thus, the removal efficiency became 32 and $79 \%$ for the cases using $\mathrm{PACl}$ and $\mathrm{FeCl}_{3}$, respectively. The reason for this large difference was that the free radical mechanism, which took place for $\mathrm{FeCl}_{3}$, made a significant influence on its oxidation potential (García Montaño et al. 2007). In the final step, since $\mathrm{Na}_{2} \mathrm{~S}$ due to the presence of $\mathrm{S}^{2-}$ ion is a strong precipitator, its addition to the effluent helped reduce the TDS concentration and drive it to the minimum achievable of 90 and $88 \mathrm{mg} / \mathrm{L}$ for $\mathrm{PACl}$ and $\mathrm{FeCl}_{3}$, respectively.

\section{TSS}

Results of the TSS depicted in Fig. 7 show that the coagulation-flocculation process caused a relative increase in the TSS concentration, especially for the case of using
Fig. 5 Effect of different stages on COD removal

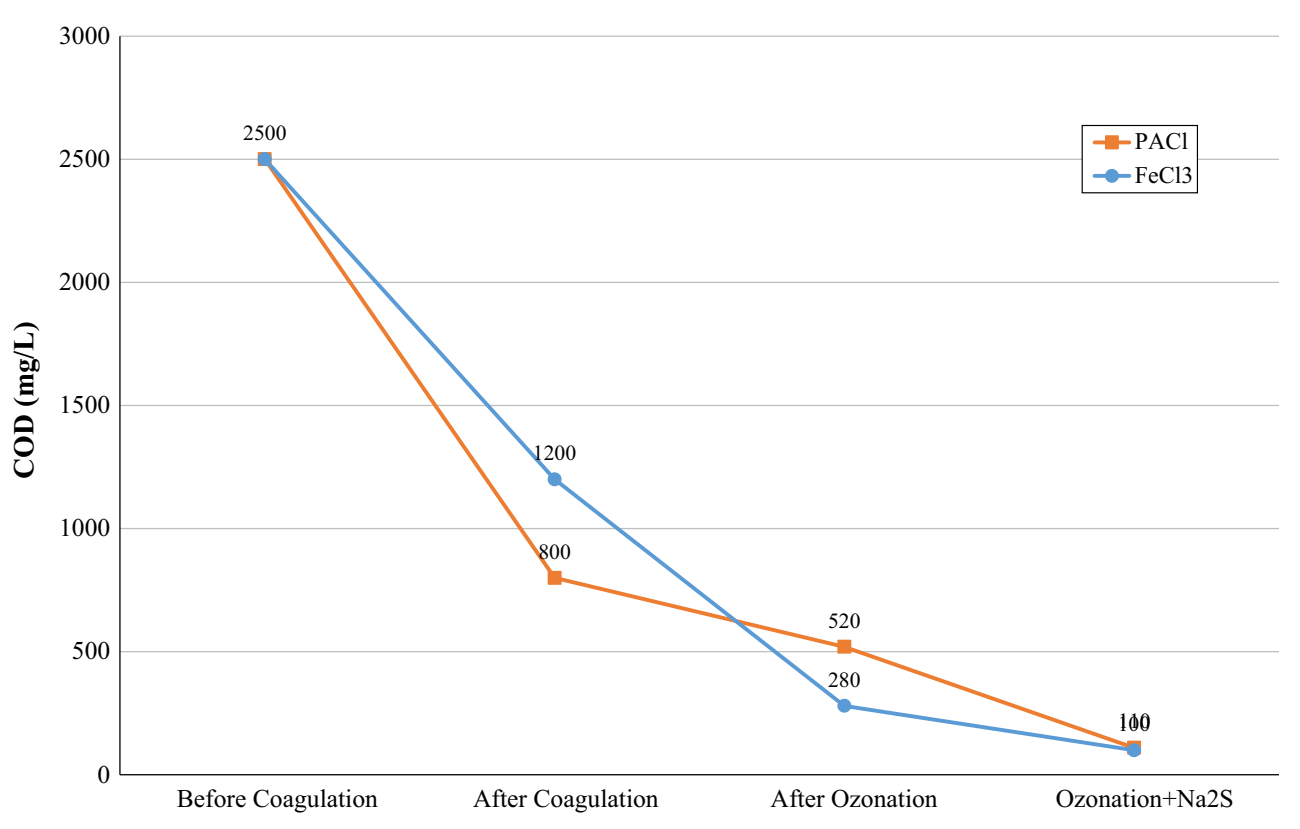




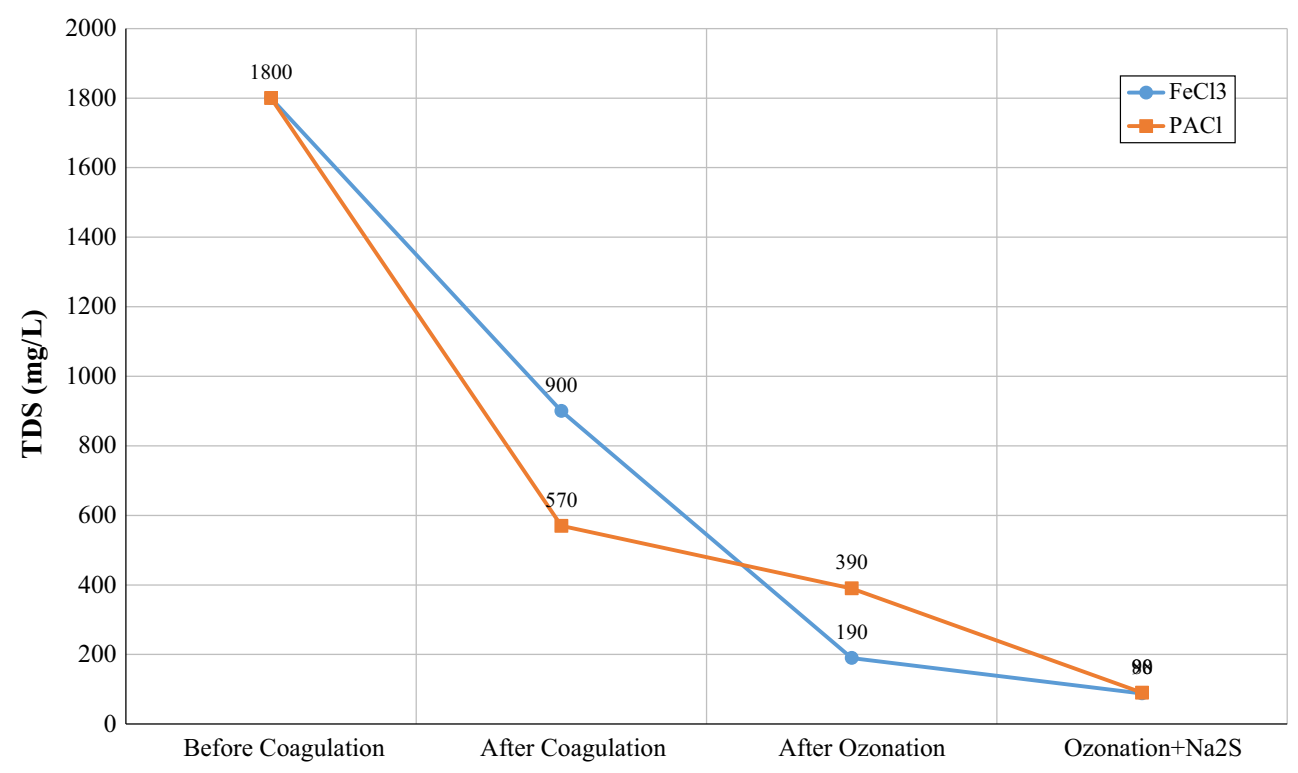

Fig. 6 Effect of different stages on TDS removal

Fig. 7 Effect of different stages on TSS removal

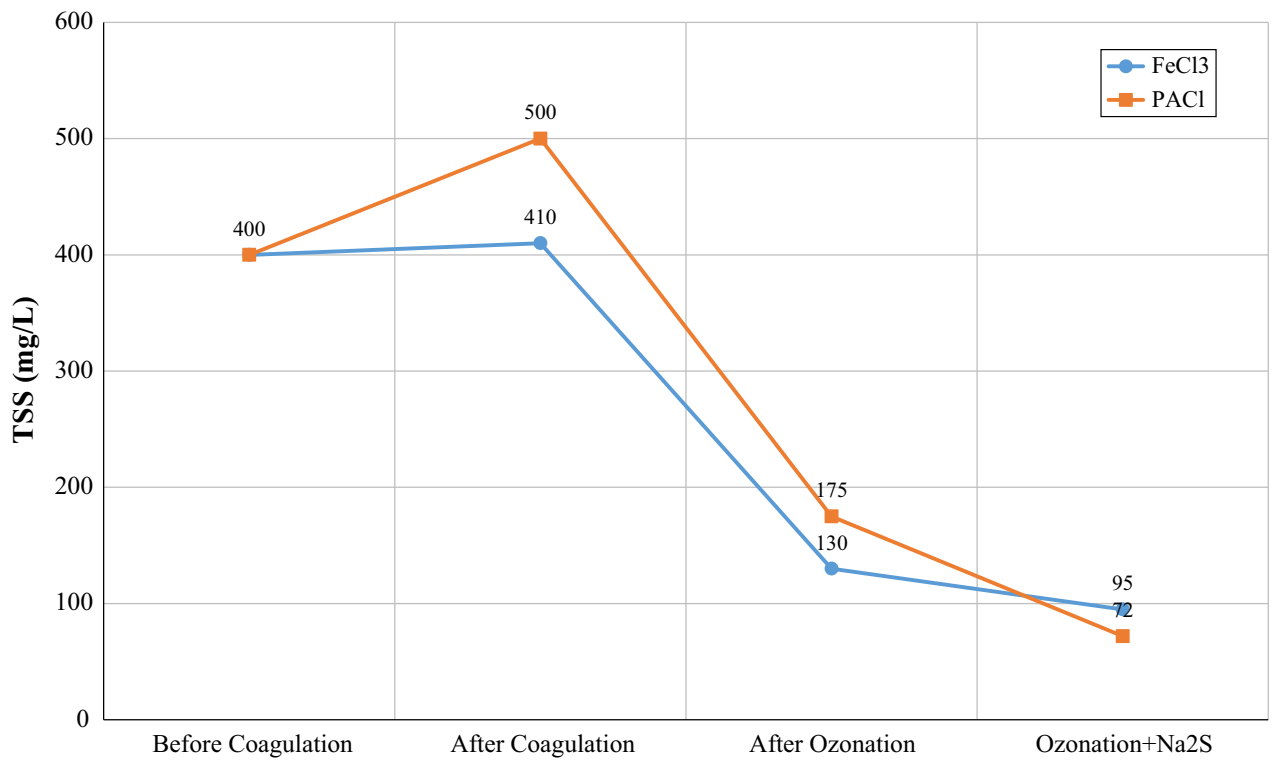

$\mathrm{FeCl}_{3}$. The suspended solids included organic and inorganic particles and immiscible liquids that entered the system by adding catalysts during drug development. The increase in the TSS concentration for $\mathrm{FeCl}_{3}$ can only be explained by inappropriate storage, since $\mathrm{FeCl}_{3}$ requires a specific storage condition. On the other hand, fluctuations are caused by discharge of different flow of effluent and are not included in the determination of coagulant concentration. Thereafter, in the ozonation process, the trend of the TSS diagram changed continuously. It can be observed that ozonation enhanced the TSS removal. In fact, ozone is a very strong oxidant which is able to convert large organic molecules into smaller ones. The removal efficiency was significantly improved in the experiments by deploying $\mathrm{Na}_{2} \mathrm{~S}$, which possessed high ion removal properties. Utilizing $\mathrm{Na}_{2} \mathrm{~S}$ in the treatment process reduced the TSS concentration to 95 and $72 \mathrm{mg} / \mathrm{L}$ for $\mathrm{PACl}$ and $\mathrm{FeCl}_{3}$, respectively.

\section{Effect of different stages of treatment on heavy metal removal}

Although the concentration of heavy metal was lower than the EPA standards, atomic absorption experiments were 
performed in order to evaluate the effect of each step during the treatment process on the removal of heavy metals.

\section{Copper $(\mathrm{Cu})$}

The results of removing copper ion by different stages of treatment are shown in Fig. 8a. The copper content in the effluent significantly decreased after the coagulation process and the removal efficiency was 77 and $57 \%$ for PACl and $\mathrm{FeCl}_{3}$, respectively. Accordingly, adding $\mathrm{PACl}$ effectively removed copper ions from the effluent. Sequentially, ozonation step dropped the $\mathrm{Cu}$ concentration gradually below $0.03 \mathrm{ppb}$ for both coagulants. A constant $\mathrm{Cu}$ content was achieved for $\mathrm{FeCl}_{3}$ after adding $\mathrm{Na}_{2} \mathrm{~S}$, while there was a relative increase for $\mathrm{PACl}$, which could be due to the variation of environmental $\mathrm{pH}$ and release of copper ions from sedimentary deposits.

$\operatorname{Iron}(\mathrm{Fe})$

Since iron is used as a catalyst during the drug manufacturing process, the effluent contained iron ions that changed the effluent color, odor, and taste. Figure $8 \mathrm{~b}$ shows the removal of iron ions at different stages of the treatment. As presented in the figure, $\mathrm{PACl}$ addition led to the iron concentration decrease to $0.13 \mathrm{mg} / \mathrm{L}$, whereas for $\mathrm{FeCl}_{3}$, it increased sharply up to $5.68 \mathrm{mg} / \mathrm{L}$, which was
Fig. 8 Effect of different stages on a $\mathrm{Cu}$ removal, b Fe removal, c Zn removal
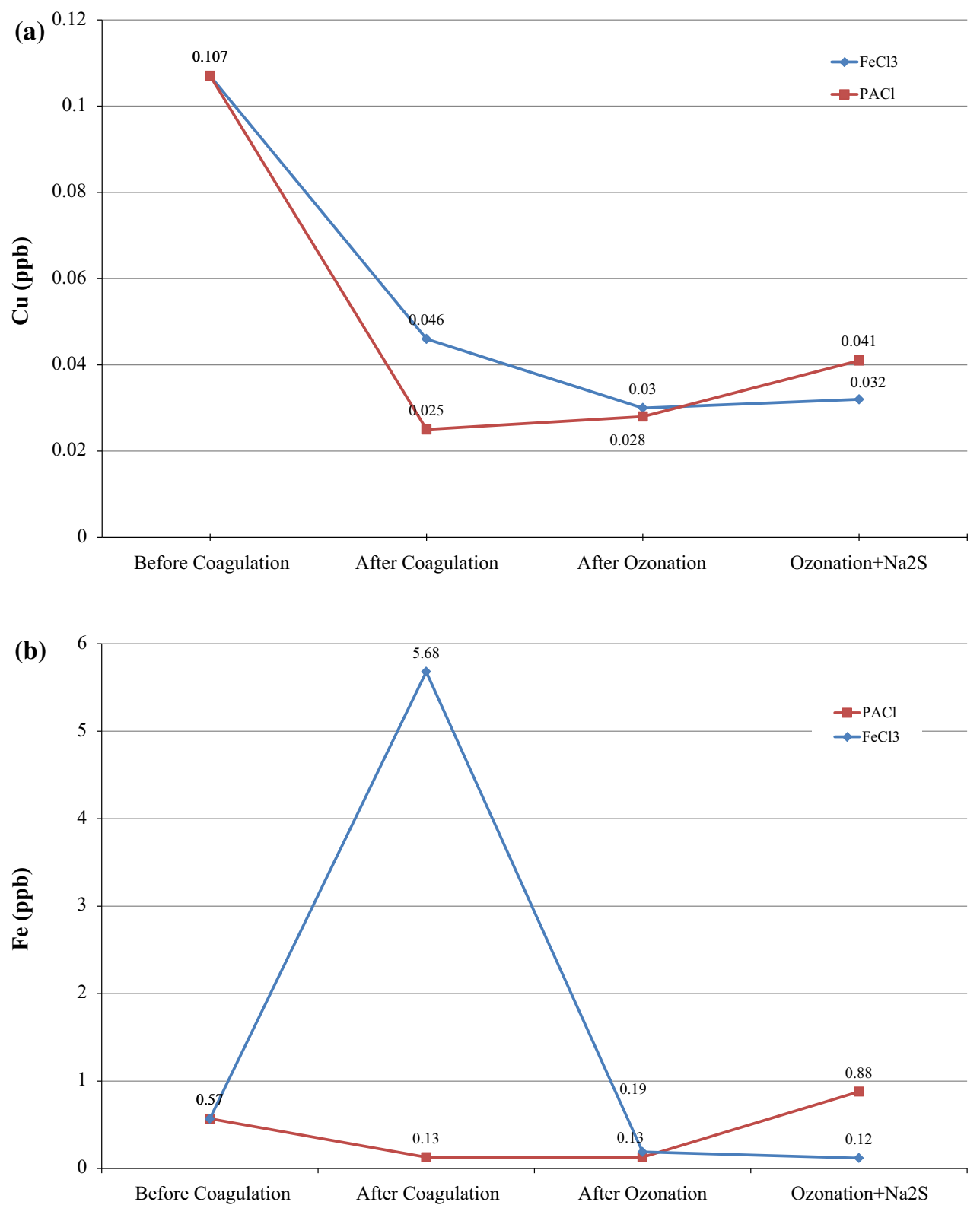
Fig. 8 continued

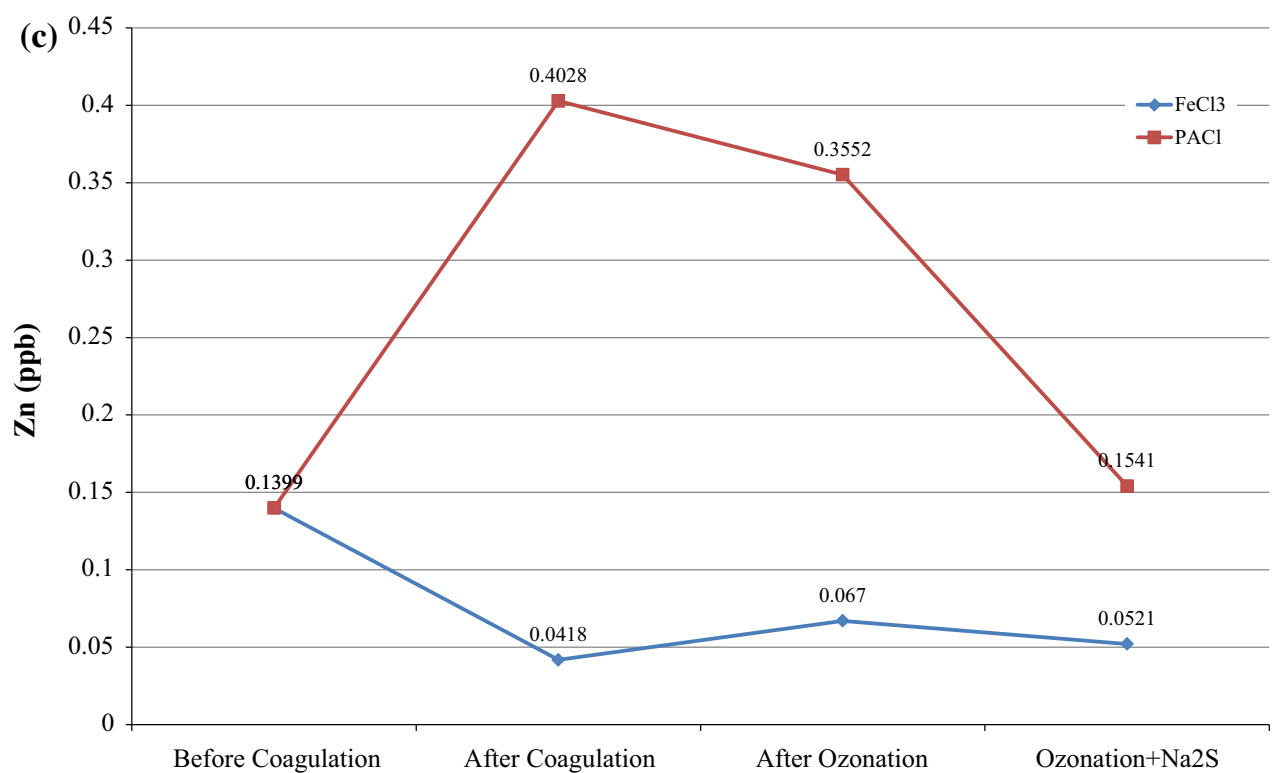

approximately 10 times greater than the initial value. This significant increase was related to the presence of iron atoms in the coagulant $\left(\mathrm{FeCl}_{3}\right)$, which caused a high concentration of $\mathrm{Fe}$ in the effluent stream. In the next step where ozonation was deployed, the oxidation dissolved Fe ions and removed most of the color, odor, and taste from the effluent. Iron is usually dissolved in water in the Fe(II) form; but, it is converted into $\mathrm{Fe}$ (III) when in contact with ozone. The dissolved ozone in water oxidizes iron to form ferric hydroxide which is very insoluble and precipitates out (Pontius and Clark 1999). Thus, a sharp decrease was made in iron concentration from 5.68 to $0.19 \mathrm{mg} / \mathrm{L}$. For $\mathrm{PACl}$ coagulant, ozonation process had no effect on the iron concentration and it was nearly constant at $0.13 \mathrm{mg} / \mathrm{L}$. Finally, adding $\mathrm{Na}_{2} \mathrm{~S}$ caused an insignificant rise of the iron concentration for $\mathrm{PACl}$, while it was relatively unchanged for $\mathrm{FeCl}_{3}$.

Zinc (Zn)

Zinc concentration was also measured in different steps of the treatment process. The results indicated that the zinc content increased significantly after coagulation with $\mathrm{PACl}$ (Fig. 8c), which can be justified only by the impurity presence in some raw materials (bauxite and calcium alumina) used to prepare PACl (Li et al. 2010). Adding ozone and $\mathrm{Na}_{2} \mathrm{~S}$ decreased the $\mathrm{Zn}$ concentration sharply from 0.4 to $0.15 \mathrm{mg} / \mathrm{L}$. The obtained results for $\mathrm{FeCl}_{3}$ showed that the coagulation process had a positive effect on the $\mathrm{Zn}$ removal, whereas ozone oxidation and $\mathrm{Na}_{2} \mathrm{~S}$ created the nearly constant concentration for $\mathrm{Zn}(0.05 \mathrm{mg} / \mathrm{L})$.

\section{Conclusion}

This study could pave the way toward enhancing the understandings of wastewater treatment systems. The findings of this study contribute to the current literature. The following conclusions can be drawn from the present study.

This study was undertaken to evaluate the performance of three coagulants and use of oxidation methods such as ozonation for reducing environmental parameters. These parameters consume some time and cost during treatment operations and have a significant impact on pharmaceutical wastewater treatment plants. In the coagulation process, $\mathrm{PACl}$ presented better performance than the other coagulants and the turbidity removal efficiency reached 97-98\% by adding $200 \mathrm{mg} / \mathrm{L}$ of PACl. Moreover, a considerable decrease was observed in most of the environmental parameters such as COD, TDS, and amount of heavy metals like Fe. However, for $\mathrm{Zn}$, it had an unfavorable effect. Ozonation improved the coagulation process and reduced most of the parameters, especially in the iron ion concentration. On the other hand, the combination of coagulation using $\mathrm{FeCl}_{3}$ and ozonation increased the removal of heavy metals from the pharmaceutical wastewater.

It can be expressed that, by means of coagulation, ozone process, and adding $\mathrm{Na}_{2} \mathrm{~S}$, it will be possible to obtain water with suitable quality, which can be reused in agriculture and irrigation.

Acknowledgments The authors would like to thank Ferdowsi University of Mashhad for the full financial support of this study. 


\section{Compliance with ethical standards}

Conflict of interest The authors have declared no conflict of interest.

\section{References}

Am Water Works Res F, Langlais B, Reckhow DA, Brink DR (1991) Ozone in water treatment: application and engineering. CRC Press, Boca Raton

Amuda O, Amoo I (2007) Coagulation/flocculation process and sludge conditioning in beverage industrial wastewater treatment. J Hazard Mater 141:778-783

Ayguna A, Yilmazb T (2010) Improvement of coagulation-flocculation process for treatment of detergent wastewaters using coagulant aids. Int J 1:97-101

Ayyildiz O, Ileri B, Sanik S (2009) Impacts of water organic load on chlorine dioxide disinfection efficacy. J Hazard Mater 168:1092-1097

Baig S, Liechti P (2001) Ozone treatment for biorefractory COD removal. Water Sci Technol 43:197-204

Errais E, Duplay J, Darragi F (2010) Textile dye removal by natural clay-case study of Fouchana Tunisian clay. Environ Technol 31:373-380

García Montaño J, Torrades I Carné F, Peral Pérez J (2007) Combination of advanced oxidation processes and biological treatments for commercial reactive azo dyes removal. Universitat Autònoma de Barcelona, Bellaterra

Gebbie P (2001) Using polyaluminium coagulants in water treatment. In: Proceedings of 64th AWIEO Conference, 5-6 September, Australia, pp 39-47

Golbaz S, Jafari AJ, Rafiee M, Kalantary RR (2014) Separate and simultaneous removal of phenol, chromium, and cyanide from aqueous solution by coagulation/precipitation: mechanisms and theory. Chem Eng J 253:251-257

Hansen KMS, Andersen HR, Ledin A (2010) Ozonation of estrogenic chemicals in biologically treated sewage. Water Sci Technol 62:649-657

Huber MM, Canonica S, Park G-Y, von Gunten U (2003) Oxidation of pharmaceuticals during ozonation and advanced oxidation processes. Environ Sci Technol 37:1016-1024

Kushwaha JP, Srivastava VC, Mall ID (2010) Treatment of dairy wastewater by inorganic coagulants: parametric and disposal studies. Water Res 44:5867-5874

Lau Y-Y, Wong Y-S, Teng T-T, Morad N, Rafatullah M, Ong S-A (2014) Coagulation-flocculation of azo dye Acid Orange 7 with green refined laterite soil. Chem Eng J 246:383-390

Lau Y-Y, Wong Y-S, Teng T-T, Morad N, Rafatullah M, Ong S-A (2015) Degradation of cationic and anionic dyes in coagulation- flocculation process using bi-functionalized silica hybrid with aluminum-ferric as auxiliary agent. RSC Adv 5:34206-34215

Lee Y, von Gunten U (2010) Oxidative transformation of micropollutants during municipal wastewater treatment: comparison of kinetic aspects of selective (chlorine, chlorine dioxide, ferrate VI, and ozone) and non-selective oxidants (hydroxyl radical). Water Res 44:555-566

Li F, Jiang J-Q, Wu S, Zhang B (2010) Preparation and performance of a high purity poly-aluminum chloride. Chem Eng J 156:64-69

Liang C-Z, Sun S-P, Li F-Y, Ong Y-K, Chung T-S (2014) Treatment of highly concentrated wastewater containing multiple synthetic dyes by a combined process of coagulation/flocculation and nanofiltration. J Membr Sci 469:306-315

$\mathrm{Ng}$ WJ (2006) Industrial wastewater treatment. Imperial College Press, London

Papić S, Koprivanac N, Božić AL (2000) Removal of reactive dyes from wastewater using $\mathrm{Fe}(\mathrm{III})$ coagulant. Color Technol 116:352-358

Pontius FW, Clark SW (1999) Drinking water quality standards, regulations and goals. AWWA, Water Quality and Treatment, New York 5

Soya K, Mihara N, Kuchar D, Kubota M, Matsuda H, Fukuta T (2010) Selective sulfidation of copper, zinc and nickel in plating wastewater using calcium sulfide. Int $\mathrm{J}$ Civil Environ Eng 2:93-97

Stumm-Zollinger E, Gordon MF (1965) Biodegradation of steroid hormones. Water Pollut Control Fed 37:1506-1510

Ternes TA, Joss A (2006) Human pharmaceuticals, hormones and fragrances: the challenge of micropollutants in urban water management. IWA Publishing, London, UK

Ternes TA, Stüber J, Herrmann N, McDowell D, Ried A, Kampmann M, Teiser B (2003) Ozonation: a tool for removal of pharmaceuticals, contrast media and musk fragrances from wastewater? Water Res 37:1976-1982

Tzoupanos N, Zouboulis A (2008) Coagulation-flocculation processes in water/wastewater treatment: the application of new generation of chemical reagents. In: Proceedings of 6th IASME/WSEAS international conference on heat transfer, thermal engineering and environment (HTE'08), 20-22 August, Rhodes, Greece, pp 309-317

Verma AK, Dash RR, Bhunia P (2012) A review on chemical coagulation/flocculation technologies for removal of colour from textile wastewaters. J Environ Manag 93:154-168

Yeap KL, Teng TT, Poh BT, Morad N, Lee KE (2014) Preparation and characterization of coagulation/flocculation behavior of a novel inorganic-organic hybrid polymer for reactive and disperse dyes removal. Chem Eng J 243:305-314

Zahrim A, Hilal N (2013) Treatment of highly concentrated dye solution by coagulation/flocculation-sand filtration and nanofiltration. Water Res Ind 3:23-34 